OPEN ACCESS

Edited by:

Xavier Manteca,

Universitat Autònoma de Barcelona,

Spain

Reviewed by:

Pol Llonch,

Universitat Autònoma de Barcelona,

Spain

Saana Isojunno,

University of St Andrews,

United Kingdom

${ }^{*}$ Correspondence:

José-Alfonso Abecia alf@unizar.es

Specialty section: This article was submitted to

Physio-logging,

a section of the journal

Frontiers in Physiology

Received: 09 May 2021 Accepted: 29 June 2021 Published: 13 August 2021

Citation:

Palacios C, Plaza J and Abecia J-A (2021) A High Cattle-Grazing Density

Alters Circadian Rhythmicity of Temperature, Heart Rate, and Activity as Measured by Implantable Bio-Loggers.

Front. Physiol. 12:707222.

doi: 10.3389/fphys.2021.707222

\section{A High Cattle-Grazing Density Alters Circadian Rhythmicity of Temperature, Heart Rate, and Activity as Measured by Implantable Bio-Loggers}

\author{
Carlos Palacios ${ }^{1}$, Javier Plaza ${ }^{1}$ and José-Alfonso Abecia ${ }^{2 *}$ \\ ${ }^{1}$ Departamento de Construcción y Agronomía, Facultad de Ciencias Agrarias y Ambientales, Universidad de Salamanca, \\ Salamanca, Spain, ²Departamento de Producción Animal y Ciencia de los Alimentos, Instituto Universitario de Investigación \\ en Ciencias Ambientales (IUCA), Universidad de Zaragoza, Zaragoza, Spain
}

Six cows managed under extensive grazing conditions were used to study the effect of moving the animals to a higher grazing density on the circadian rhythms of temperature $(T)$, heart rate $(\mathrm{HR})$, and activity $(\mathrm{ACT})$, which were recorded by implantable bio-loggers. Cows were maintained at a density of 1.5 livestock units per hectare (LSUs/ha; low density, LD) until they were moved to a grazing area at 128 LSUs/ha (high density, HD). Animals were implanted subcutaneously with a T, HR, and ACT bio-logger, which was programmed to record data at 5-min intervals. For each animal, cosinor rhythmometry (the study of circadian rhythms by fitting a sine wave to a time series) was applied to the data recorded over 5 days in LD and HD. Mean Midline Estimating Statistic of Rhythm (MESOR; the average value around which the variable oscillates), amplitude (difference between the peak and the mean value of a wave), and acrophase (timing of peak activity) were calculated and evaluated statistically. Differences between mean day and nighttime values, and mean $\mathrm{LD}$ and $\mathrm{HD}$ values were calculated. Cows presented cosinor curves that fit a 24-h rhythm $(p<0.001)$ in T, HR, and ACT at both densities. MESOR (T: 37.98 vs. $38.02^{\circ} \mathrm{C}$; HR: 69.12 vs. 65.91 bpm; ACT: 49.39 vs. $40.41 \mathrm{mg}$, for LD and HD, respectively) and amplitude (T: 0.28 vs. $0.28^{\circ} \mathrm{C}$; HR: 4.12 vs. 3.14 bpm; ACT: 18.14 vs. 11.28 mg, respectively) did not differ significantly between the two densities; however, significant $(p<0.05)$ differences between densities occurred in the acrophase of the three variables; specifically, the $T$ acrophase was $2 \mathrm{~h}$ later at HD (22:45 h) than LD (20:45 h), and HR (LD: 19:51; HD: 16:49 h) and ACT acrophases 3 and 2 h earlier at HD than LD (LD: 14:47; HD: 12:49 h), respectively. T and ACT differed significantly $\left(p<0.01\right.$ ) between daytime (mean \pm SE; $37.92 \pm 0.19^{\circ} \mathrm{C}$, $40.39 \pm 4.74 \mathrm{mg})$ and nighttime $\left(38.14 \pm 0.17^{\circ} \mathrm{C}, 29.93 \pm 5.66 \mathrm{mg}\right)$. In conclusion, our study suggests that a high animal grazing density might exacerbate the social competence for valuable resources for animals, resulting in shifting the circadian rhythmicity of temperature, heart rate, and activity of the cows, advancing or delaying their acrophases.

Keywords: cattle, density, bio-loggers, circadian rhythm, temperature, heart rate, activity 


\section{INTRODUCTION}

Environmental factors such as temperature (T), humidity, and solar radiation have significant direct and indirect effects on livestock production (Nienaber et al., 1999). Climate change has been generating temperatures that negatively affect the availability of food for animals maintained in grazing systems. Heat and nutritional stress are the most influential factors in the productive and reproductive successes in cattle (Maurya et al., 2004; Marai et al., 2007). Different production practices, some of which involve high animal density and rotational grazing in order to improve soil conditions and the yield and quality of forage (Murphy et al., 1986) have been implemented. Organic livestock production involves the environmentally sustainable animal management, with animal welfare as a priority, and with a high consumer demand (Von Borell and Sørensen, 2004). Stocking density is one of the factors that can produce stress in the animals (Loudon et al., 2019) and organic management might be a means of preventing this stress, through its specific legislation regarding low animal densities.

To collect information that indicates the level of stress suffered by the animal, there are animal-attached devices that record body temperature, heart rate (HR), and activity (ACT) of an individual. For instance, HR measures the activity of the autonomous nervous system (Sanmiguel et al., 2018), commonly used in animal welfare research to measure changes in the sympathetic-vagal balance in mammals and birds in relation to the circadian rhythm (Brauner et al., 2010), management, health, psychological, and environmental stressors (Stubsjoen et al., 2015). The stress-induced hyperthermia response is a relatively short-lasting rise in body temperature in response to stress (Bouwknecht et al., 2007). Stress-induced pathologies can be accompanied by changes in circadian rhythms; therefore, a study of these changes might be helpful in confirming whether a group of animals is under a stressor that ensures animal welfare. Temporal evaluation of a fluctuating variable that has a rhythmic variation will provide a forecast for making decisions, because biological rhythms and the state of the health of an animal and a population are correlated (Piccione and Caola, 2002).

In recent years, the development of bio-sensors for monitoring real-time responses in, for example, body temperature, respiration and heart rate, blood pressure, or activity of the animals, have helped to understand how external factors (e.g., housing, diet, and management) affect an animal's resiliency to stressors (Neethirajan et al., 2017). Data recorded by these devices can be analyzed by cosinor analysis, which is often used in the analysis of biological time series that demonstrate predictable rhythms fitting a sine wave to a time series. Since it has been observed that changes in feeding time, housing procedures, or social cues can affect biological rhythms in animal experiments (Piccione and Caola, 2002), we hypothesize that changes in animal density of grazing cows could lead to a modification of their circadian rhythmicity.

The objective of this study was to use subcutaneous bio-loggers to investigate the circadian changes in some physiological variables of cows that have been subjected to rotational grazing with a high livestock density in a short period of time.

\section{MATERIALS AND METHODS}

The Ethics Committee for Animal Experiments at the University of Salamanca approved the procedures performed in this study (reference PI/2020/956). The care and use of animals were in accordance with the Spanish Policy for Animal Protection (RD 53/2013), which meets the European Union Directive 2010/63 on the protection of animals used for experimental and other scientific purposes.

\section{Animals}

The study was performed on an organic agricultural and livestock farm in Larrodrigo, Spain $\left(40^{\circ} 44^{\prime} \mathrm{N} ; 5^{\circ} 26^{\prime} \mathrm{W}\right)$. The farm was in an area where cereal fields are interspersed among cultivated pastures and holm oak trees. The main cultivated species were forage species that were destined for consumption by the cattle herd. The cattle herd was divided into large grazing groups that grazed fenced pastures that had holm oak, although there were areas of meadows with grasslands. In general, the stocking density in the extensive management was low, although it varied based on the size of the enclosure in which they had been allocated. Animals were always kept outdoors under natural photoperiodic conditions (15 June: sunrise $0650 \mathrm{~h}$, sunset 21:15 h), and water was available ad libitum.

In early April, a group of 90 Morucha $\times$ Charolais cows, which had a mean live weight $( \pm S D)$ of $550 \pm 22 \mathrm{~kg}$, was allocated to a fenced grazing area that provided 1.5 livestock units per hectare (LSU/ha; low density, LD). In early June, six cows were selected to be implanted with bio-loggers. They were selected based on their age (5-6 years-old) and homogenous liveweight $(540 \pm 10 \mathrm{~kg})$. After 1 week, the herd was moved to a smaller grazing area where the density was $128 \mathrm{LSUs} / \mathrm{ha}$ (high density, HD). Both areas were adjacent, so they shared similar characteristics of orography, insolation, and vegetation.

\section{Measurements}

Six cows were surgically implanted with a subcutaneous T, HR, and ACT bio-logger (DST centi-HRT ACT, Star Oddi, Gardabaer, Iceland), which was programmed to record data at 5-min intervals. After the experiment, the bio-loggers were removed and the data were downloaded using a communication box and Mercury software v5.83 (Star Oddi, Gardabaer, Iceland). The data were recorded over 5 days in LD after the logger had been implanted and the first 5 days in HD (the transition day was excluded). The DST activity loggers measure acceleration in three dimensions, in relation to earth's gravity field. Each logger is calibrated by Star-Oddi, and static acceleration for each axis and then calculated using the following steps. First, the center of the range of values for each axis is measured and extracted from the raw accelerometer value, then each axis is normalized to $1 \mathrm{~g}$ based on the range measured for each axis during rotation ( $\mathrm{g}$ is the acceleration of gravity or $9.8 \mathrm{~m} \mathrm{~s}^{-2}$ ). The algorithm then uses this calibration information to separate the static and dynamic acceleration components of each measurement. The algorithm calculates the external acceleration (EA) as a vectorial sum of dynamic body acceleration (veDBA; reported by the software in $\mathrm{mg}$ ), which 
has been correlated with HR in cattle (Miwa et al., 2015). Mean, maximum, and minimum ambient $\mathrm{T}$ and relative humidity $(\mathrm{RH}, \%)$ on the days of the experiment were collected from the meteorological station on the farm.

\section{Surgical Implantation}

For implantation, the cows were immobilized in the handling race, with the head held and the left leg of the cow extended to reach the armpit. Cows were sedated with $0.05 \mathrm{mg} / \mathrm{kg}$ xylazine i.m. (Xilagesic, Calier, Barcelona, Spain), the skin was cleaned for surgery, and a 2-ml local anesthetic s.c. (lidocaine hydrochloride, Anesvet, Ovejero, León, Spain) was injected. An incision was made in the skin, and a pocket to hold the sensor was created. The bio-logger was placed subcutaneous on the left thorax, above the heart, and with the sensor axis parallel to the heart axis. The incision was closed by 2-3 sutures of surgery silk and was sprayed with aluminum spray (Aluspray, Vetoquinol, Madrid, Spain). The bio-loggers were sterilized by a 24 -h immersion in $0.55 \%$ ortho-phthalaldehyde (CIDEX-OPA solution, Johnson \& Johnson, New Jersey, United States). Similar procedures were performed for the sensor withdrawal.

\section{Statistical Analysis}

To test the significance of the differences in T, HR, and ACT between the two grazing densities and between day (07:0021:00 h) and night (22:00-06:00 h), we used the SPSS MIXED procedure (IBM Corp, 2019), in a model that included grazing density (LD or HD) and day/night time as fixed effects, and their interaction, with cows considered as random effects. Since correlation between residuals of the observations (autocorrelation) is assumed, a first-order autoregressive (AR1) covariance structure was used, so that, the variance is assumed to be heterogeneous and the correlations between the two adjacent time points decline across measurement occasions. The 5-min observations records of each variable were grouped hourly, and recoded for day and night times. Circadian rhythms in T, HR, and ACT were graphed by fitting the time series measurements of each cow to the cosine curve of a 24-h activity rhythm, which was obtained by the cosinor method at the Cosinor on-line platform (Molcan, 2019). ${ }^{1}$ Midline Estimating Statistic of Rhythm (MESOR, the average value around which the variable oscillates), amplitude (the difference between the peak and the mean value of a wave), and acrophase (the time of peak activity) were calculated for each variable in each individual. Cosine curves are $y_{t}=M+A$ $\cos ((2 \pi / 24) t+\varphi)+\epsilon_{t}$, where $y_{t}$ is an observation at time $t$, $\mathrm{M}$ is the MESOR, $\mathrm{A}$ is the amplitude, and $\varphi$ is the acrophase. The error term $\epsilon_{t}$ is assumed to be independently normally distributed with mean 0 and unknown constant variance $\sigma 2$. To test for rhythmicity, an F-test compared the (re-parameterized) cosine model with the nonrhythmic model yt $=\mathrm{M}+\epsilon_{\mathrm{t}}$. A $p<0.05$ indicates that the time series fit a 24-h rhythm. Thereafter, the data were pooled and the mean 24-h cosinor curve for each of the three parameters was calculated, and the cosinor values of the two densities were compared by an ANOVA. The results were expressed as mean \pm SE. Values of $p<0.05$ were considered statistically significant.

\section{RESULTS}

On the farm at the time of the experiment, maximum $\mathrm{T}$ and lowest $\mathrm{RH}$ occurred in the midday (Figure 1). Temperature and ACT were significantly $(p<0.01)$ affected by light/dark period of the day, but HR was significantly $(p<0.001)$ affected by grazing density, with a significant interaction between density and light/dark period ( $p<0.001$; Table 1). Mean day and night values of T, HR, and ACT under both grazing densities are presented in Table 2. No differences between mean $\mathrm{T}$ at $\mathrm{LD}$ $\left(37.98 \pm 0.01^{\circ} \mathrm{C}\right)$ and $\mathrm{HD}\left(38.02 \pm 0.04^{\circ} \mathrm{C}\right)$ were observed. HR was significantly $(p<0.001)$ higher at LD than at $\mathrm{HD}(67.72 \pm 0.32$

${ }^{1}$ https://cosinor.online

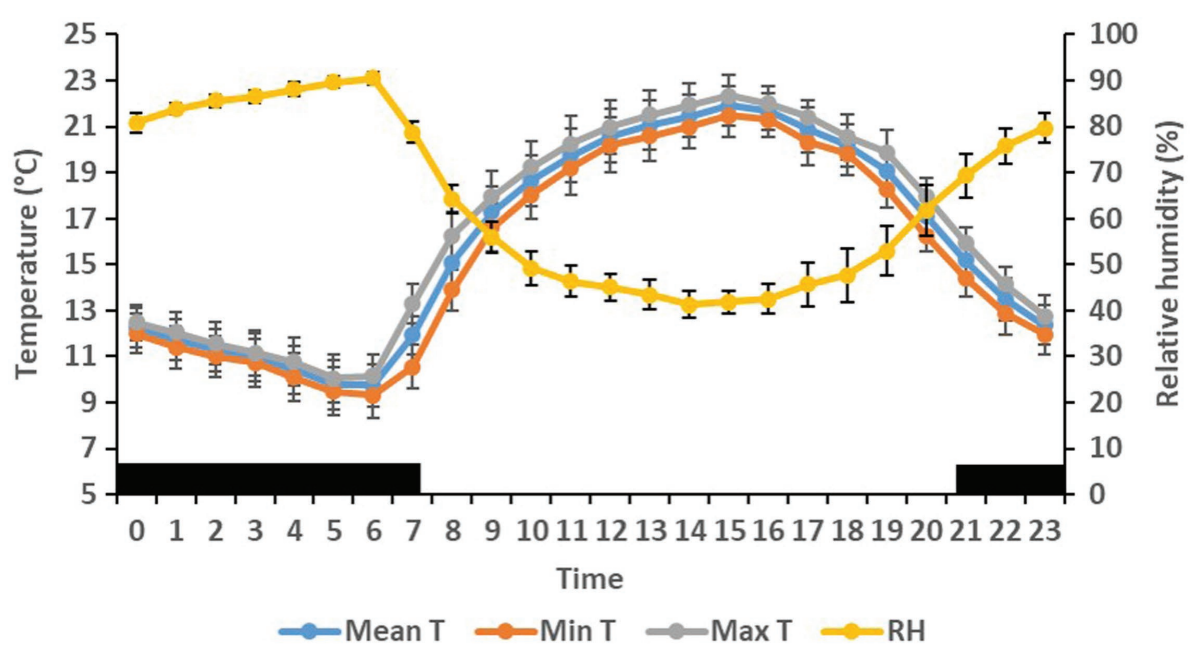

FIGURE 1 | Mean $\left( \pm\right.$ SEM) maximum (Max), minimum (Min), mean ambient temperature $\left(T,{ }^{\circ} \mathrm{C}\right)$, and relative humidity $(\mathrm{RH}, \%)$ on the farm in which six cows were exposed to low and high density grazing. 
vs. $64.61 \pm 0.20 \mathrm{bpm})$, and ACT during daytime (40.39 $\pm 4.74 \mathrm{mg})$ was significantly higher $(p<0.001)$ than at nighttime $(29.93 \pm 5.66 \mathrm{mg})$. The mean values of a 24 -h period of the three variables in the six cows at the two densities are presented in Figures 2-4. Cows experienced a dramatic reduction in $\mathrm{T}$ at the beginning of the day (Figure 5), which coincided with increases in HR and ACT. Cows exhibited the least movement at night.

The six cows had cosinor curves that fitted a 24-h rhythm $(p<0.0001)$ in T, HR, and ACT at both grazing densities (Figure 5). MESOR and amplitude of the three variables did not differ significantly between the two densities (Table 3); however, the acrophase of T, HR, and ACT differed significantly $(p<0.05)$ between densities, such that the time of peak $\mathrm{T}$ was $2 \mathrm{~h}$ later at $\mathrm{HD}$ than it was at $\mathrm{LD}$, and peak $\mathrm{HR}$ and ACT were 3 and $2 \mathrm{~h}$, respectively, earlier at $\mathrm{HD}$ than they were at LD (Table 3).

\section{DISCUSSION}

The experiment demonstrated that an increase in grazing density induced changes in the circadian rhythmicity of $\mathrm{T}, \mathrm{HR}$, and ACT in cows, delaying $\mathrm{T}$ acrophase and advancing $\mathrm{HR}$ and ACT acrophases. Previous studies described environmentally induced changes in the acrophase of several metabolic or physiological variables in cows. In Holstein cattle, acrophases

TABLE 1 | Matrix of coefficients of the mixed model applied to test the significance of the differences in temperature $(T)$, heart rate $(\mathrm{HR})$, and activity (ACT) of six cows that were maintained at 1.5 livestock units per hectare (LSUs/ ha; low density, LD) and were moved to a grazing area that had a density of 128 LSUs/ha (high density, HD).

\begin{tabular}{lrrrr}
\hline & Value & SE & $\boldsymbol{t}$-value & $\boldsymbol{p}$-value \\
\hline Temperature & & & & \\
Intercept & 37.490 & 31.226 & 1.200 & 0.229 \\
Density & 0.038 & 0.037 & 1.019 & 0.308 \\
Day/Night & -0.037 & 0.012 & -3.098 & 0.002 \\
Interaction & 0.003 & 0.016 & 0.176 & 0.860 \\
$\quad$ Heart Rate & & & & \\
Intercept & 66.711 & 0.834 & 79.957 & 0.000 \\
Density & -5.637 & 0.806 & -6.993 & 0.000 \\
Day/Night & 0.324 & 0.770 & 0.402 & 0.674 \\
Interaction & 4.033 & 1.066 & 3.78 & 0.000 \\
Activity & & & & \\
Intercept & 33.621 & 3.950 & 8.511 & 0.000 \\
Density & 0.286 & 3.812 & 0.075 & 0.940 \\
Day/Night & 24.669 & 3.638 & 6.780 & 0.000 \\
Interaction & -9.530 & 5.036 & -1.892 & 0.058
\end{tabular}

of the daily rhythms of acute phase proteins were about $2 \mathrm{~h}$ later in July than they were in January (Giannetto et al., 2012). In another study, differences affected daily rhythms in blood urea and ammonia concentrations; specifically, cows fed at 16:00 h exhibited nocturnal acrophases in urea, and cows fed at 08:00 or 16:00 h, exhibited diurnal acrophases in ammonia (Piccione et al., 2007). Those authors suggested that external stimuli, such as feeding time, have a direct effect on the rhythms of the metabolites involved in liver function, and on the hypothetic interaction between circadian clocks located in the liver and the mean circadian system. A large experiment involving horses, sheep, goats, and cattle, that were housed in 1-hectare paddocks or in boxes, demonstrated that stable groups of cows and horses experienced an earlier acrophase of the rhythm of ACT (Giannetto et al., 2018), which occurred in our experiment, where HD induced an advance in the acrophase of activity in the cows. Thus, the response of the animals at HD grazing conditions in our experiment were similar to the response of animals in stabled conditions, which exhibited a diminution of their locomotor activity.

Like any circadian rhythm, the rhythm of body $\mathrm{T}$ is characterized mainly by its period, which in the absence of external temporal cues is usually very close to $24 \mathrm{~h}$ (Refinetti and Menaker, 1992). Body $\mathrm{T}$ in cattle has a pronounced circadian rhythm, with a minimum in the morning and a maximum in the late afternoon (Kendall and Webster, 2009), although the circadian rhythm of body $\mathrm{T}$ in dairy cows is dynamic and is affected by the physiological state of the animal and environmental stressors. In ruminants, stressors cause a short-lived increase in core body T, i.e., hyperthermia (Lambert and Carder, 2017) by stimulating the sympathetic pathway of the autonomic nervous system and altering the thermoregulatory set point (Pedernera-Romano et al., 2010). Although it was not supported statistically, a pattern of increased in body temperature at night in our experiment may have reflected such hyperthermia related to social stress. It is also likely that the slight body temperature increase at night during $\mathrm{HD}$ be a consequence of sleeping/ resting more closely together, due to a smaller grazing area. In a diurnal wild species, the tree shrew, subjected to socially induced stress (Fuchs and Flügge, 2002), males were exposed to a dominant male for about $1 \mathrm{~h}$ daily, and this social stress increased the mean nocturnal temperature by $0.37^{\circ} \mathrm{C}$, which was an emotional fever. Increases in nocturnal temperature occur in humans who are experiencing depression (Souetre et al., 1988). The cows in our experiment probably experienced higher inter-cow competition at HD than they did at LD, and experienced a higher nocturnal temperature, which may be a

TABLE 2 | Mean $\left( \pm\right.$ SEM) daytime (07:00-21:00 h) and nighttime (22:00-06:00 h) temperature $\left(\mathrm{T},{ }^{\circ} \mathrm{C}\right)$, heart rate (HR, bpm), and activity (ACT, mg) of six cows that were maintained at 1.5 LSUs/ha (LD) and were moved to a grazing area that had a density of $128 \mathrm{LSUs} / \mathrm{ha}(\mathrm{HD})$.

\begin{tabular}{|c|c|c|c|c|c|c|}
\hline & \multicolumn{2}{|c|}{$\mathbf{T}$} & \multicolumn{2}{|c|}{ HR } & \multicolumn{2}{|c|}{ ACT } \\
\hline & LD $(n=6)$ & $\mathrm{HD}(n=6)$ & $\operatorname{LD}(n=6)$ & $\mathrm{HD}(n=6)$ & LD $(n=6)$ & $\mathrm{HD}(n=6)$ \\
\hline
\end{tabular}

$a, b$ indicate $p<0.05$ between densities; $x, y$ indicate $p<0.05$ between day and night. 


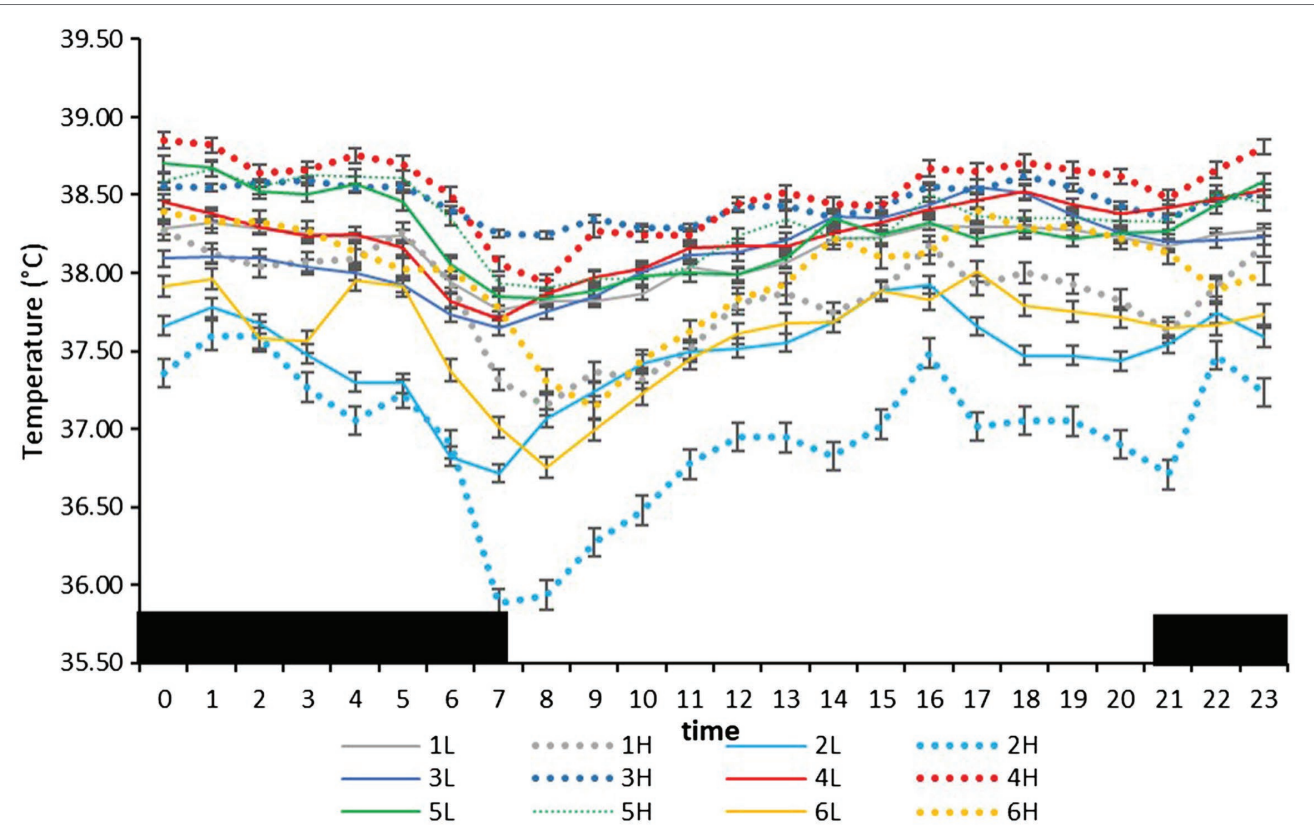

FIGURE 2 | Mean $\left( \pm\right.$ SEM) body temperature $\left({ }^{\circ} \mathrm{C}\right)$ of six cows measured by subcutaneous bio-loggers on 5 days of grazing at 1.5 LSUs/ha (low density, l) followed by 5 days of grazing at a density of 128 LSUs/ha (high density, H). Black areas indicate night (22:00-06:00 h).

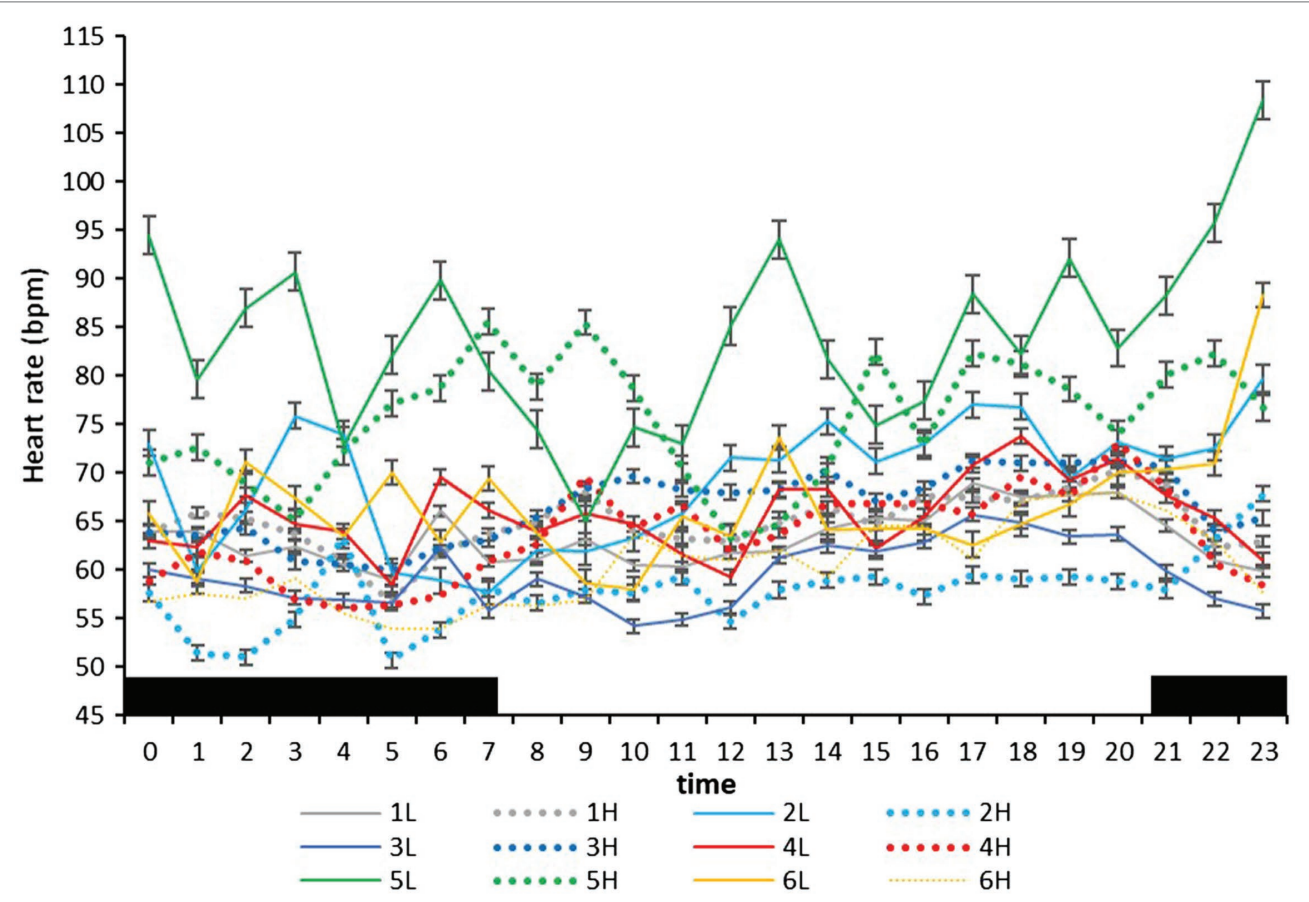

FIGURE 3 | Mean ( $($ SEM) heart rate (bpm) of six cows measured by subcutaneous bio-loggers on 5 days of grazing at 1.5 LSUs/ha (low density, L) followed by 5 days of grazing at a density of 128 LSUs/ha (high density, H). Black areas indicate night (22:00-06:00 h).

reflection of stress. In addition, competition for food can cause stress. For instance, in a study in which mice given a small piece of cheese in the presence of a cage mate who was given a large piece, mice exhibited a large increase in surface body temperature (Watanabe, 2017). Circadian variations in HR and arterial blood pressure in farm animal species is well known (Piccione et al., 2005), and HR has been used as a measure of autonomic regulation of cardiac activity in farm animals to assess stress and well-being under various housing and management conditions (von Borell et al., 2007). 


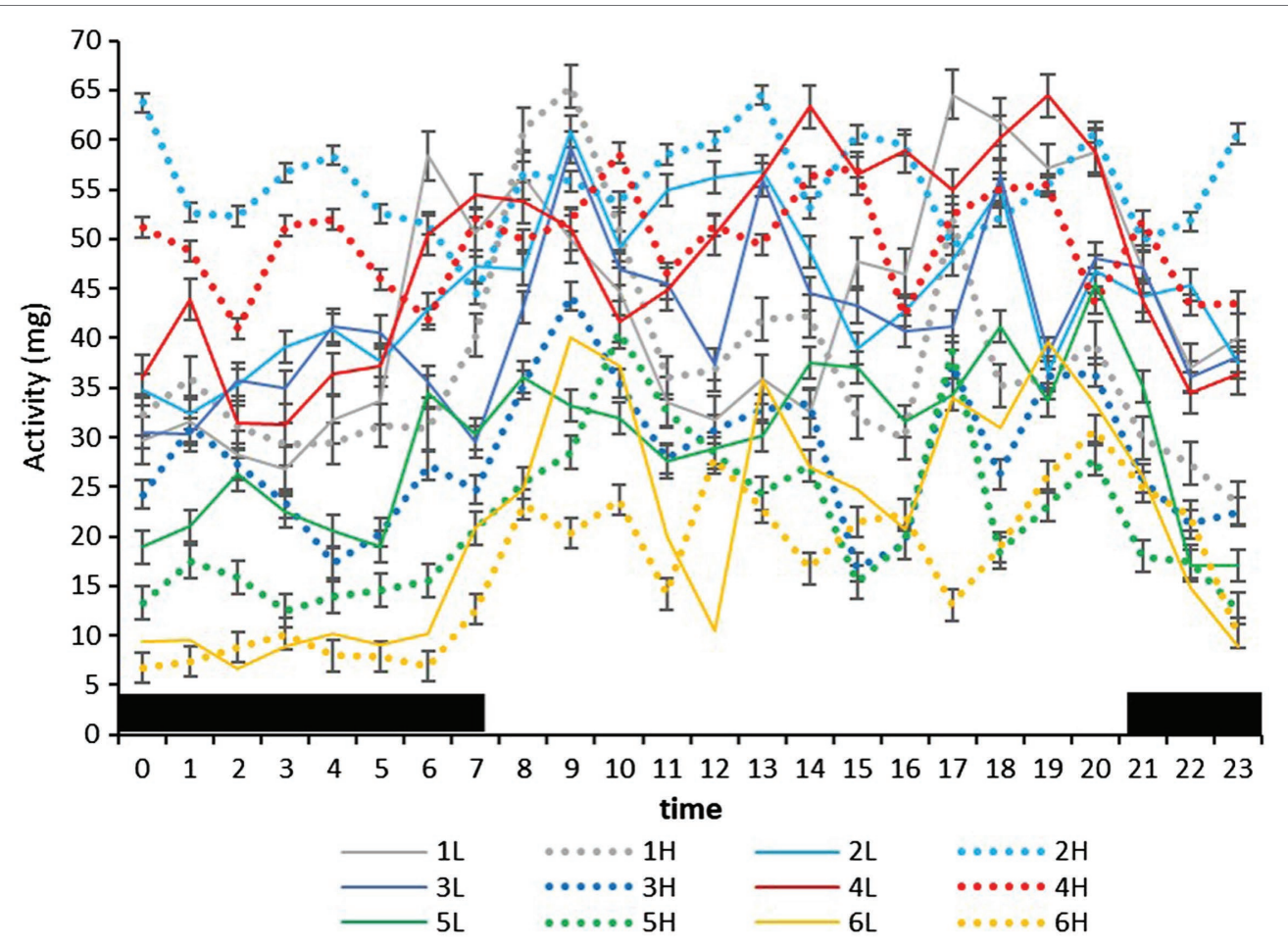

FIGURE 4 | Mean ( \pm SEM) activity (standard acceleration of gravity, $g$ ) of six cows measured by subcutaneous bio-loggers on 5 days of grazing at 1.5 LSUs/ha (low density, L) followed by 5 days of grazing at a density of 128 LSUs/ha (high density, H). Black areas indicate night (22:00-06:00 h).

Furthermore, changes in HR are a possible early indicator of metabolic stress in cows (Erdmann et al., 2018). The circadian rhythm in activity is disrupted under chronic stress in animals and humans, and it can be less marked if the animal is diseased. For instance, the average level of ACT of a cow on a given day and variations throughout the day differed among specific states such as estrus, lameness, mastitis, and circadian variations in activity appeared to be particularly sensitive and changed 1-2 days before the farmer detected a disorder (Veissier et al., 1989). Probably, grazing density has been a disruption that can modify the circadian rhythmicity of the physiological variables under study.

Although, the light-dark cycle caused by the earth's rotation is the most important synchronizing agent of circadian rhythms in mammals, a variety of nonphotic factors, such as social cues, can affect circadian rhythmicity (Piccione and Caola, 2002). In hamsters, social interactions, cage cleaning, noveltyinduced activity, and immobilization can shift the phase of free-running activity rhythms (Mrosovsky et al., 1989; Van Reeth et al., 1991). Rats subjected to social defeat exhibited pronounced changes in daily rhythms in body $\mathrm{T}$ and ACT. After defeat, the amplitude of the $\mathrm{T}$ rhythm was strongly reduced, mainly because of an increase in $\mathrm{T}$ in the circadian resting phase, but returned to baseline levels after 5-10 days. Group size influences the behavior of grazing cows, including feeding and aggression. Rind and Phillips (1999) observed differences in time spent in, e.g., ruminating and aggression, and the distance from their nearest neighbor among groups of cows that contained four, eight, or 16 animals. Inter-cow competition and walking rate, while grazing were highest in the largest group, and animals in this group spent more time grooming, which often is a displacement activity, which might indicate increased stress. Apparently, regrouping and increases in stocking density have negative effects on cows, and the effects of regrouping are aggravated by concurrent increases in density, and by changes in group and pen size (Talebi et al., 2014). In sheep, ewes in small flocks spent less time grazing than did ewes in large flocks (Penning et al., 1993).

Ruminants maintained in extensive grazing systems have 3-5 grazing events, with the most intense occurring in the morning and in late afternoon/early evening (Gregorini, 2012). At night, they exhibit less intense grazing events, which are $10-15 \%$ of daily grazing time. In our experiment, ACT was lowest at night, and cows had 2-4 periods of high movement in the day, although the timing was influenced by grazing density. The absence of differences in activity between grazing densities in the day, and the significant interaction between grazing density and the timing of the peak in the three variables suggest that the change to a higher animal density influenced not only the behavior of the cows in the day and at night, but also the relationship between physiological variables such as T and HR.

\section{CONCLUSION}

In conclusion, our study suggests that a high animal grazing density might exacerbate the competition for valuable resources for animals, resulting in shifting the circadian rhythmicity of 


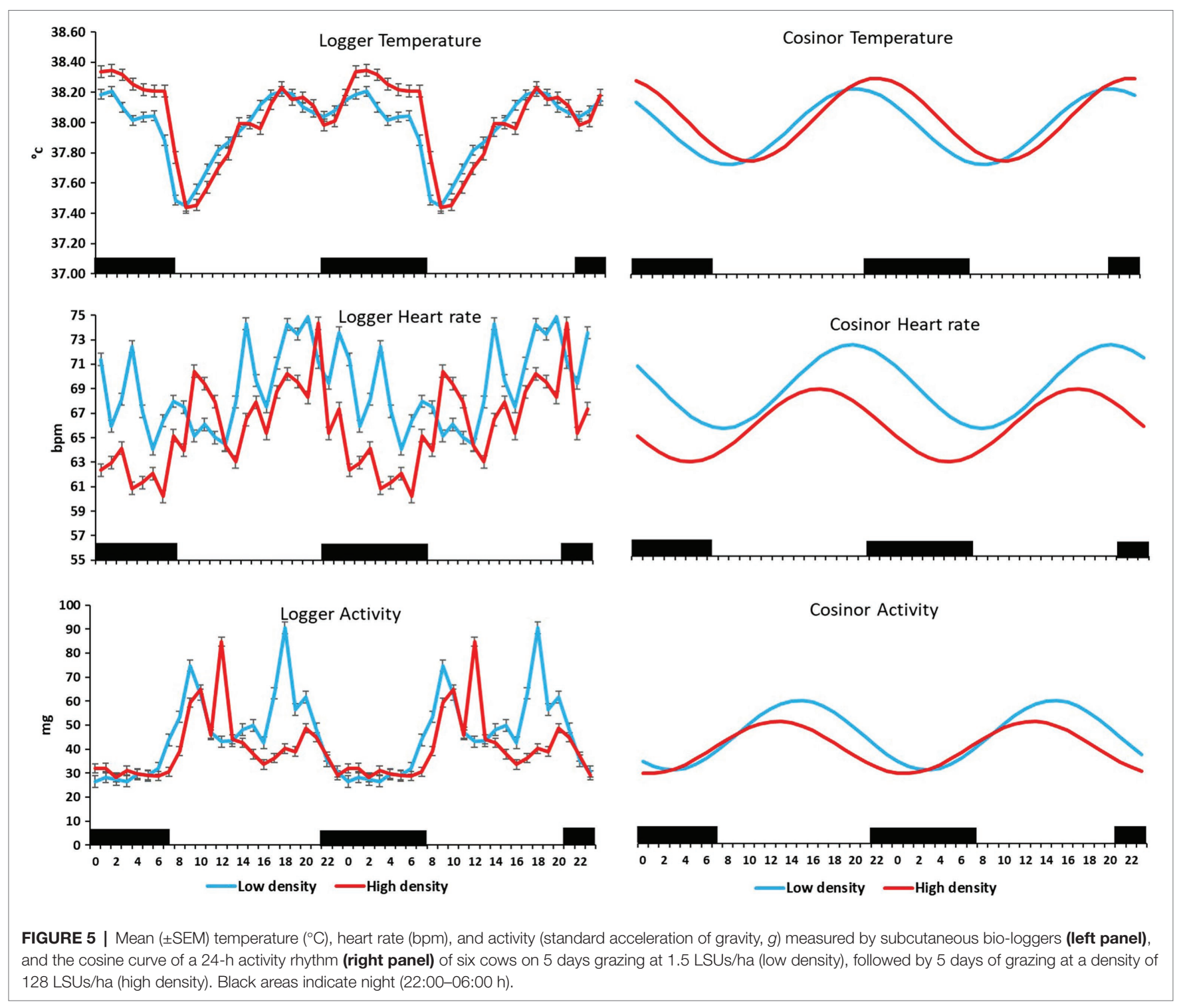

TABLE 3 | Mean ( $( \pm$ SEM) Midline Estimating Statistic of Rhythm (MESOR), amplitude (the difference between the peak and the mean value of a wave), and acrophase (the time of peak activity) of the cosine curve of a 24 -h activity rhythm in temperature $\left({ }^{\circ} \mathrm{C}\right)$, heart rate $(\mathrm{bpm})$, and activity $(\mathrm{mg})$, of six cows maintained at $1.5 \mathrm{LSU} / \mathrm{ha}$ (LD) and were moved to a grazing area that had a density of $128 \mathrm{LSUS} / \mathrm{ha}(\mathrm{HD})$.

\begin{tabular}{|c|c|c|c|c|c|c|}
\hline & \multicolumn{2}{|c|}{ Temperature } & \multicolumn{2}{|c|}{ Heart rate } & \multicolumn{2}{|c|}{ Activity } \\
\hline & LD $(n=6)$ & $\mathrm{HD}(n=6)$ & LD $(n=6)$ & $\mathrm{HD}(n=6)$ & LD $(n=6)$ & HD $(n=6)$ \\
\hline Amplitude & $0.28 \pm 0.01$ & $0.28 \pm 0.04$ & $4.12 \pm 0.88$ & $3.14 \pm 0.71$ & $18.14 \pm 3.52$ & $11.28 \pm 2.67$ \\
\hline Acrophase & $20: 45 \pm 0.74^{a}$ & $22: 45 \pm 0.24^{b}$ & $19: 51 \pm 1.05^{\mathrm{a}}$ & $16: 49 \pm 1.37^{b}$ & $14: 47 \pm 0.70^{a}$ & $12: 49 \pm 0.46^{b}$ \\
\hline
\end{tabular}

a, $b$ indicate $p<0.05$.

temperature, heart rate, and activity of the cows, advancing or delaying their acrophases. The results of this study highlighted the ability of these bio-loggers to monitor some physiological variables of cows, discriminating changes when animals are managed at different grazing densities.

\section{DATA AVAILABILITY STATEMENT}

The raw data supporting the conclusions of this article will be made available by the authors, without undue reservation. 


\section{ETHICS STATEMENT}

The animal study was reviewed and approved by the Ethics Committee for Animal Experiments at the University of Salamanca. Written informed consent was obtained from the owners for the participation of their animals in this study.

\section{AUTHOR CONTRIBUTIONS}

All authors listed have made a substantial, direct and intellectual contribution to the work, and approved it for publication.

\section{REFERENCES}

Bouwknecht, A. J., Olivier, B., and Paylor, R. E. (2007). The stress-induced hyperthermia paradigm as a physiological animal model for anxiety: a review of pharmacological and genetic studies in the mouse. Neurosci. Biobehav. Rev. 31, 41-59. doi: 10.1016/j.neubiorev.2006.02.002

Brauner, A. E., Kurjiaka, D. T., Ibragimov, A., and Baldwin, A. L. (2010). Impact of cage size and enrichment (tube and shelf) on heart rate variability in rats. Scand. J. Lab. Anim. Sci. 37, 185-201. doi: 10.23675/sjlas.v37i3.215

Erdmann, S., Mohr, E., Derno, M., Tuchscherer, A., Schäff, C., Börner, S., et al. (2018). Indices of heart rate variability as potential early markers of metabolic stress and compromised regulatory capacity in dried-off highyielding dairy cows. Animal 12, 1451-1461. doi: 10.1017/S1751731117002725

Fuchs, E., and Flügge, G. (2002). Social stress in tree shrews: effects on physiology, brain function, and behavior of subordinate individuals. Pharmacol. Biochem. Behav. 73, 247-258. doi: 10.1016/S0091-3057(02)00795-5

Giannetto, C., Casella, S., Giudice, E., Marafioti, S., Fazio, F., and Piccione, G. (2012). Daily rhythms of acute phase proteins in cattle under different natural environmental conditions. Livest. Sci. 149, 195-200. doi: 10.1016/j. livsci.2012.07.006

Giannetto, C., Giudice, E., Acri, G., Fazio, F., and Piccione, G. (2018). Interspecies comparison of daily total locomotor activity monitoring in different management conditions. J. Vet. Behav. 23, 97-100. doi: 10.1016/j.jveb.2017.11.002

Gregorini, P. (2012). Diurnal grazing pattern: its physiological basis and strategic management. Anim. Prod. Sci. 52, 416-430. doi: 10.1071/AN11250

IBM Corp (2019). IBM SPSS Statistics for Windows, Version 26.0. Armonk, NY: IBM Corp.

Kendall, P. E., and Webster, J. R. (2009). Season and physiological status affects the circadian body temperature rhythm of dairy cows. Livest. Sci. 125, 155-160. doi: 10.1016/j.livsci.2009.04.004

Lambert, H. S., and Carder, G. (2017). Looking into the eyes of a cow: can eye whites be used as a measure of emotional state? Appl. Anim. Behav. Sci. 186, 1-6. doi: 10.1016/j.applanim.2016.11.005

Loudon, K., Tarr, G., Pethick, D. W., Lean, I. J., Polkinghorne, R., Mason, M., et al. (2019). The use of biochemical measurements to identify pre-slaughter stress in pasture finished beef cattle. Animals 9:503. doi: 10.3390/ani9080503

Marai, I. F. M., El-Darawany, A. A., Fadiel, A., and Abdel-Hafez, M. A. M. (2007). Physiological traits as affected by heat stress in sheep: a review. Small Rumin. Res. 71, 1-12. doi: 10.1016/j.smallrumres.2006.10.003

Maurya, V. P., Naqvi, S. M. K., and Mittal, J. P. (2004). Effect of dietary energy level on physiological responses and reproductive performance of Malpura sheep in the hot semi-arid regions of India. Small Rumin. Res. 55, 117-122. doi: $10.1016 /$ j.smallrumres.2003.12.008

Miwa, M., Oishi, K., Nakagawa, Y., Maeno, H., Anzai, H., Kumagai, H., et al. (2015). Application of overall dynamic body acceleration as a proxy for estimating the energy expenditure of grazing farm animals: relationship with heart rate. PLoS One 10:e0128042. doi: 10.1371/journal.pone.0128042

Molcan, L. (2019). Time distributed data analysis by cosinor. bioRxiv [Preprint]. doi: $10.1101 / 805960$

Mrosovsky, N., Reebs, S. G., Honrado, G. I., and Salmon, P. A. (1989). Behavioural entrainment of circadian rhythms. Experientia 45, 696-702. doi: 10.1007/BF01974561

\section{FUNDING}

This research was funded by "Diputación de Salamanca", Spain, Project 18V131 463AC06 from USAL. The "Instituto de Investigación en Ciencias Ambientales de Aragón” (IUCA) from University of Zaragoza, for funding publication fees.

\section{ACKNOWLEDGMENTS}

We thank the owners of the "Finca de Gallegos" farm, for their kind collaboration, M. Criado for his work with the animals, and Bruce MacWhirter for the English edition of the manuscript.

Murphy, W., Rice, J., and Dugdale, D. (1986). Dairy farm feeding and income effects of using Voisin grazing management of permanent pastures. Am. J. Altern. Agric. 1, 147-152. doi: 10.1017/S0889189300001211

Neethirajan, S., Tuteja, S. K., Huang, S. T., and Kelton, D. (2017). Recent advancement in biosensors technology for animal and livestock health management. Biosens. Bioelectron. 15, 398-407. doi: 10.1016/j. bios.2017.07.015

Nienaber, J. A., Hahn, G. L., and Eigenberg, R. A. (1999). Quantifying livestock responses for heat stress management: a review. Int. J. Biometeorol. 42, 183-188. doi: 10.1007/s004840050103

Pedernera-Romano, C., Ruiz de la Torre, J. L., Badiella, L., and Manteca, X. (2010). Effect of perphenazine enanthate on open-field test behaviour and stress-induced hyperthermia in domestic sheep. Pharmacol. Biochem. Behav. 94, 329-332. doi: 10.1016/j.pbb.2009.09.013

Penning, P. D., Parsons, A. J., Newman, J. A., Orr, R. J., and Harvey, A. (1993). The effects of group size on grazing time in sheep. Appl. Anim. Behav. Sci. 37, 101-109. doi: 10.1016/0168-1591(93)90103-V

Piccione, G., and Caola, G. (2002). Biological rhythm in livestock: a review. J. Vet. Sci. 3, 145-157. doi: 10.4142/jvs.2002.3.3.145

Piccione, G., Caola, G., and Refinetti, R. (2005). Temporal relationships of 21 physiological variables in horse and sheep. Comp. Biochem. Physiol. A Mol. Integr. Physiol. 142, 389-396. doi: 10.1016/j.cbpa.2005.07.019

Piccione, G., Grasso, F., Fazio, F., Assenza, A., and Caola, G. (2007). Influence of different schedules of feeding on daily rhythms of blood urea and ammonia concentration in cows. Biol. Rhythm. Res. 38, 133-139. doi: 10.1080/09291010600913964

Refinetti, R., and Menaker, M. (1992). The circadian rhythm of body temperature. Physiol. Behav. 51, 613-637. doi: 10.1016/0031-9384(92)90188-8

Rind, M. I., and Phillips, C. J. C. (1999). The effects of group size on the ingestive and social behaviour of grazing dairy cows. Anim. Sci. 68, 589-596. doi: $10.1017 /$ S135772980005061X

Sanmiguel, R. A., Hernández, F. A. P., Piso, D. Y. T., Rubio, M. D. R. P., Sierra, L. M. P., and DiGiacinto, A. (2018). Requerimientos para la medición de indicadores de estrés invasivos y no invasivos en producción animal. Rev. Invest. Vet. Peru 29, 15-30. doi: 10.15381/rivep.v29i1.14195

Souêtre, E., Salvati, E., Belugou, J. L., Robert, P., Brunet, G., and Darcourt, G. (1988). Antidepressant effect of 5-methoxypsoralen: a preliminary report. Psychopharmacology 95, 430-431. doi: 10.1007/BF00181962

Stubsjoen, S. M., Knappe-Poindecker, M., Langbein, J., Fjeldaas, T., and Bohlin, J. (2015). Assessment of chronic stress in sheep (part II): exploring heart rate variability as a non-invasive measure to evaluate cardiac regulation. Small Rumin. Res. 133, 30-35. doi: 10.1016/j.smallrumres.2015.10.026

Talebi, A., von Keyserlingk, M. A. G., Telezhenko, E., and Weary, D. M. (2014). Reduced stocking density mitigates the negative effects of regrouping in dairy cattle. J. Dairy Sci. 97, 1358-1363. doi: 10.3168/jds.2013-6921

Van Reeth, O., Hinch, D., Tecco, J. M., and Turek, F. W. (1991). The effects of short periods of immobilization on the hamster circadian clock. Brain Res. 545, 208-214. doi: 10.1016/0006-8993(91)91288-c

Veissier, I., Le Neindre, P., and Trillat, G. (1989). The use of circadian behaviour to measure adaptation of calves to changes in their environment. Appl. Anim. Behav. Sci. 22, 1-12. doi: 10.1016/0168-1591(89)90075-0 
von Borell, E., Dobson, H., and Prunier, A. (2007). Stress, behaviour and reproductive performance in female cattle and pigs. Horm. Behav. 52, 130-138. doi: 10.1016/j.yhbeh.2007.03.014

Von Borell, E., and Sørensen, J. T. (2004). Organic livestock production in Europe: aims, rules and trends with special emphasis on animal health and welfare. Livest. Prod. Sci. 90, 3-9. doi: 10.1016/j.livprodsci.2004.07.003

Watanabe, S. (2017). Social inequality aversion in mice: analysis with stressinduced hyperthermia and behavioral preference. Learn. Motiv. 59, 38-46. doi: 10.1016/j.lmot.2017.08.002

Conflict of Interest: The authors declare that the research was conducted in the absence of any commercial or financial relationships that could be construed as a potential conflict of interest.
Publisher's Note: All claims expressed in this article are solely those of the authors and do not necessarily represent those of their affiliated organizations, or those of the publisher, the editors and the reviewers. Any product that may be evaluated in this article, or claim that may be made by its manufacturer, is not guaranteed or endorsed by the publisher.

Copyright (C) 2021 Palacios, Plaza and Abecia. This is an open-access article distributed under the terms of the Creative Commons Attribution License (CC BY). The use, distribution or reproduction in other forums is permitted, provided the original author(s) and the copyright owner(s) are credited and that the original publication in this journal is cited, in accordance with accepted academic practice. No use, distribution or reproduction is permitted which does not comply with these terms. 